\title{
Protective effects of ellagic acid against tetrachloride-induced cirrhosis in mice through the inhibition of reactive oxygen species formation and angiogenesis
}

\author{
YUAN DING, LIZHOU WANG, JIE SONG and SHI ZHOU \\ Department of Interventional Radiology, The Affiliated Hospital of Guizhou \\ Medical University, Guiyang, Guizhou 550004, P.R. China
}

Received November 28, 2015; Accepted December 9, 2016

DOI: $10.3892 / \mathrm{etm} .2017 .4966$

\begin{abstract}
Ellagic acid has been proven to have anticancer, antimutation, antimicrobial and antiviral functions. The present study investigated whether treatment with ellagic acid was able to prevent tetrachloride (CCl4)-induced cirrhosis through the inhibition of reactive oxygen species (ROS) formation and angiogenesis. $\mathrm{CCl}_{4}$ diluted in olive oil at a final concentration of $10 \%$ was used to induce a cirrhosis model. A total of 40 mice were random allocated into four groups, as follows: Control, cirrhosis model, $7.5 \mathrm{mg} / \mathrm{kg}$ ellagic acid and $15 \mathrm{mg} / \mathrm{kg}$ ellagic acid groups. In the control group, mice were given normal saline. The results indicated that ellagic acid exerted a protective effect, evidently preventing $\mathrm{CCl}_{4}$-induced cirrhosis. In addition, treatment with ellagic acid significantly inhibited collagen I and inducible nitric oxide synthase protein expression levels in $\mathrm{CCl}_{4}$-induced cirrhosis mice. Oxidative stress and ROS formation were also significantly reduced by ellagic acid treatment. The protein expression levels of vascular endothelial growth factor (VEGF) and VEGF receptor 2 (VEGFR2), and the caspase-3 activity were significantly inhibited by treatment with ellagic acid. In conclusions, these results suggest that ellagic acid exerted protective effects against $\mathrm{CCl}_{4}$-induced cirrhosis through the inhibition of ROS formation and angiogenesis.
\end{abstract}

\section{Introduction}

Liver cirrhosis is a chronic liver disease characterized by diffuse liver fibrosis, and formation of pseudolobules and regenerative nodules (1). Clinically, cirrhosis affects multiple systems, with manifestations including liver function lesion and portal hypertension (2). At advanced stages, it has severe complications, such as hemorrhage of the digestive tract,

Correspondence to: Mr. Shi Zhou, Department of Interventional Radiology, The Affiliated Hospital of Guizhou Medical University, 28 Gui Yi Street, Guiyang, Guizhou 550004, P.R. China

E-mail: shipa0659638150@163.com

Key words: ellagic acid, tetrachloride-induced cirrhosis hepatic encephalopathy and secondary infection (3). The main pathogenesis factor of liver cirrhosis is viral hepatitis, while it may also be caused by cholestasis, circulatory disturbance, and virulence drugs, metabolic disorders, dystrophia, immunologic derangement and other unclear causes (4).

Oxidative damage is associated with numerous chronic diseases. Mice with liver cirrhosis have been demonstrated to present with evident imbalance of oxidization and oxidation resistance (5). Under normal conditions, the liver oxidative system is dynamically balanced with the antioxidant system (6). Factors causing liver injuries lead to lipid peroxidation of hepatic tissues through activation of oxygen molecules (7). The synergistic effects of oxygen molecules increase the free radical production and lipid peroxidation, thus damaging the liver. Subsequently, deterioration of the inflammation reaction is observed, causing liver injury $(8,9)$. Such pathological changes result in difficulty in the treatment of liver cirrhosis patients (10).

Ellagic acid (Fig. 1) has various biological activities, including antioxidant, anti-mutation and inhibitory effects on human immunodeficiency virus (11). In addition, ellagic acid is an effective coagulant and has favorable inhibition effects on various bacteria and viruses (12). Treatment with ellagic acid has been observed to protect wound surface from the invasion of bacteria and from infection, inhibiting ulceration (13). Furthermore, it has been demonstrated that ellagic acid has depressurization and sedation functions (14). However, whether ellagic acid prevent cirrhosis has not yet been reported. Therefore, the present study aimed to examine whether the protective effects of ellagic acid prevented tetrachloride $\left(\mathrm{CCl}_{4}\right)$-induced cirrhosis and to assess the potential mechanisms.

\section{Materials and methods}

Animal model of cirrhosis. All study protocols were approved by the Animal Ethics Committee of The Affiliated Hospital of Guizhou Medical University (Guiyang, China). A total of 40 specific-pathogen-free C57BL/6 male mice (weight, 20 2 g; age, 6-7 weeks) were acquired by the Experimental Animal Center of Guizhou Medical University and maintained on standard chow in an $25.1 \pm 1^{\circ} \mathrm{C}$ atmosphere with a 12-h dark/light 
cycle. Next, 40 mice were random allocated into four groups as follows: Control, $\mathrm{CCl}_{4}$-induced cirrhosis model, $7.5 \mathrm{mg} / \mathrm{kg}$ ellagic acid and $15 \mathrm{mg} / \mathrm{kg}$ ellagic acid groups. In the control group, mice were given normal saline $(100 \mu \mathrm{l}$; 11 weeks; via oral gavage, once daily for two days). $\mathrm{CCl}_{4}$ (Sinopharm Chemical Reagent Co., Ltd., Shanghai, China) was diluted into olive oil at a final concentration of $10 \%$, and then this was used to induce a cirrhosis model by administration three times a week for 6 weeks, at a dose of $2 \mathrm{ml} / \mathrm{kg}$ each time (intraperitoneal injection). $\mathrm{CCl}_{4}$-injected mice were divided into a further three groups ( $\mathrm{n}=10$ each) after 6 weeks of $\mathrm{CCl}_{4}$ administration, including the cirrhosis model, $7.5 \mathrm{mg} / \mathrm{kg}$ ellagic acid and $15 \mathrm{mg} / \mathrm{kg}$ ellagic acid groups for 5 weeks.

Serum biochemistry analysis. Whole blood samples were collected from the eye socket using $2-3 \%$ chloral hydrate and centrifuged at $1,000 \mathrm{x}$ g for $20 \mathrm{~min}$ at $4^{\circ} \mathrm{C}$ to collect serum. Serum levels of alanine aminotransferase (ALT; C009-2), aspartate aminotransferase (AST; C010-2) and albumin (ALB; A028-1; all Nanjing Jiancheng Biology Engineering Institute) were read at a wavelength of $560 \mathrm{~nm}$ using a spectrophotometer (GE Healthcare Life Sciences, Chicago, IL, USA).

Hepatic histopathology. Following treatment with ellagic acid, mice were sacrificed via decollation after anesthetization with $30 \mathrm{mg} / \mathrm{kg}$ pentobarbital sodium (Sinopharm Chemical Reagent Co., Ltd.). Following treatment with ellagic acid, liver tissue samples were acquired using $10 \%$ chloral hydrate and fixed with $4 \%$ formaldehyde. Next, the tissue samples were dehydrated in a graded ethanol series, cleared in xylene and embedded in paraffin. The tissues were then sectioned into 4- $\mu \mathrm{m}$ samples and stained hematoxylin and eosin (H\&E). Images were captured using a microscope (TCS SP2; Leica Microsystems GmbH, Wetzlar, Germany).

Analysis of collagen I content of tissues. Total RNA from liver tissue samples was isolated using TRI reagent (Sigma Aldrich, St. Louis, MO, USA) according to the manufacturer's protocol. Next, $2 \mu \mathrm{g}$ total RNA was subjected to reverse transcription using a c-DNA synthesis kit (Revert Aid First Strand c-DNA synthesis kit; Fermentas; Thermo Fisher Scientific, Inc., Waltham, MA, USA). cDNA was then amplified by polymerase chain reaction (PCR) using specific primers of collagen I: Forward, 5'-CAG AGTGGAAGAGCGATTA-3', and reverse, 5'-CAAGGACAG TGTAGGTGAA-3'. Amplification was performed in a DNA Thermal Cycler (Applied Biosystems; Thermo Fisher Scientific, Inc.) at $95^{\circ} \mathrm{C}$ for $10 \mathrm{~min}$, followed by 40 cycles of $94^{\circ} \mathrm{C}$ for $30 \mathrm{sec}$, $60^{\circ} \mathrm{C}$ for $30 \mathrm{sec}$ and $72^{\circ} \mathrm{C}$ for $40 \mathrm{sec}$.

Reactive oxygen species (ROS) formation. Liver tissue $(50 \mathrm{mg})$ sections were collected and homogenized for $10 \mathrm{sec}$ at $12,000 \mathrm{x} g$ for $10 \mathrm{~min}$ at $4^{\circ} \mathrm{C}$. Total protein in the samples was measured using a BCA assay reagent (Beyotime Institute of Biotechnology, Nanjing, China). Subsequently, $30 \mu \mathrm{g}$ protein was used to measure ROS formation (S0033; Beyotime Institute of Biotechnology) Cells were incubated with DCFH-DA for $20 \mathrm{~min}$ at $37^{\circ} \mathrm{C}$, and washed with PBS. ROS formation was measured at a wavelength of $488 \mathrm{~nm}$ and emission wavelength of $525 \mathrm{~nm}$ using a spectrophotometer (GE Healthcare Life Sciences, Chicago, IL, USA).
Oxidative stress assay. Whole blood samples were collected from the eye socket using $10 \%$ chloral hydrate and centrifuged at $1,000 \mathrm{x} \mathrm{g}$ for $20 \mathrm{~min}$ at $4^{\circ} \mathrm{C}$ to collect serum. After cooling to room temperature, $150 \mu \mathrm{l}$ serum was used to detect the activities of glutathione peroxidase (GSH-Px; A005), glutathione (GSH; A006-2), superoxide dismutase (SOD; A001-3) and malondialdehyde (MDA; A003-1; all Nanjing Jiancheng Biology Engineering Institute) using ELISA kits and a spectrophotometer (GE Healthcare Life Sciences) according to the manufacturer's instructions.

Western blot analysis. Following treatment with ellagic acid, liver tissue samples were acquired and homogenized for $10 \mathrm{sec}$ at $12,000 \mathrm{x} \mathrm{g}$ for $10 \mathrm{~min}$ at $4^{\circ} \mathrm{C}$. Total protein was measured using a $\mathrm{BCA}$ assay reagent (Beyotime Institute of Biotechnology), and then $50 \mu \mathrm{g}$ protein was subjected to 10-12\% SDS-PAGE and electrotransferred onto a polyvinylidene difluoride membrane (BD Biosciences, San Jose, CA, USA). The membrane was blocked in 5\% non-fat milk in phosphate-buffered saline (PBS; $\mathrm{pH}$ 7.4) for $2 \mathrm{~h}$, and subsequently incubated overnight at $4^{\circ} \mathrm{C}$ with the following primary antibodies: Anti-inducible nitric oxide synthase (iNOS; 1:400; sc-649; Santa Cruz Biotechnology, Inc., Dallas, TX, USA), anti-vascular endothelial growth factor (VEGF; 1:500; sc-13083; Santa Cruz Biotechnology, Inc.), anti-VEGF receptor 2 (VEGFR2; 1:3,000; ab11939; Abcam, Cambridge, UK) and $\beta$-actin (1:500; sc-7210; Santa Cruz Biotechnology, Inc.). Next, the membranes were washed with PBS and incubated with horseradish peroxidase-conjugated goat anti-mouse IgG secondary antibody (1:5,000; 7074; Cell Signaling Technology, Inc., Danvers, MA, USA) at room temperature for $2 \mathrm{~h}$. Protein expression in the samples was detected by Amersham ECL Prime western blotting detection reagent (GE Healthcare Life Sciences, Piscataway, NJ, USA) and analyzed using AlphaEase FC (FluorChem FC2) software (Cell Biosciences Inc., Santa Clara, CA, USA).

Determination of caspase-3 activity. Following treatment with ellagic acid, liver tissue samples were acquired and homogenized via centrifugation at $12,000 \mathrm{x}$ g for $10 \mathrm{~min}$ at $4^{\circ} \mathrm{C}$. Total protein was measured using BCA assay reagent (Beyotime Institute of Biotechnology), and $5 \mu \mathrm{g}$ protein was incubated with Ac-DEVD-pNA-caspase-3 activity kit (C1115; Beyotime Institute of Biotechnology) for $30 \mathrm{~min}$ at room temperature. The absorbance values were assessed at $405 \mathrm{~nm}$ using a spectrophotometer (GE Healthcare Life Sciences) according to the manufacturer's protocol.

Statistical analysis. Data are expressed as the mean \pm standard error of the mean. Statistically significant differences between the groups were determined using the one-way analysis of variance test, followed by the post-hoc Tukey's test. $\mathrm{P}<0.05$ was considered to indicate statistically significant differences.

\section{Results}

Protective effects of ellagic acid against $\mathrm{CCl}_{4}$-induced cirrhosis. At the beginning of the experiment, the protective effects of ellagic acid against $\mathrm{CCl}_{4}$-induced cirrhosis were determined. As shown in Fig. 2 ( $\mathrm{P}=0.0018,0.0073$ and 0.0089), 
<smiles>O=c1oc2c(O)c(O)cc3c(=O)oc4c(O)c(O)cc1c4c23</smiles>

Figure 1. Chemical structure of ellagic acid.

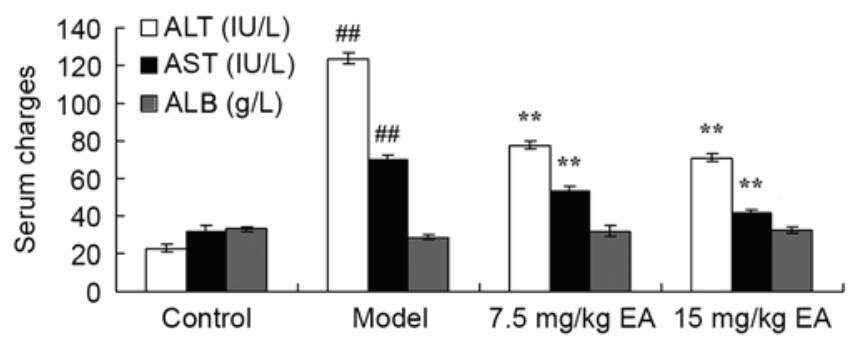

Figure 2. Serum levels of ALT, ALB and AST in cirrhosis mice showing the protective effects of EA against $\mathrm{CCl}_{4}$-induced cirrhosis. ${ }^{\# \#} \mathrm{P}<0.01$ vs. control group; ${ }^{* *} \mathrm{P}<0.01$ vs. model group. $\mathrm{CCl}_{4}$, tetrachloride; EA, ellagic acid; ALT, alanine aminotransferase; AST, aspartate aminotransferase.

the serum levels of ALT, AST and ALB in the cirrhosis model mice were effectively increased when compared with those in the control group. Following treatment with ellagic acid for 5 weeks, the serum levels of ALT, AST and ALB were effectively reduced in the cirrhosis mice (Fig. 2; $\mathrm{P}=0.0056,0.0093$ and 0.0072). These data suggest that ellagic acid reduced ALT, AST and ALB serum levels and thus may serve as an adjuvant for the treatment of cirrhosis.

Hepatic histopathological changes following ellagic acid treatment. H\&E staining of liver tissue samples was used to analyze the effect of ellagic acid in the cirrhosis mice. As shown in Fig. 3, $\mathrm{CCl}_{4}$-induced cirrhosis was markedly observed in mice of the model group, compared with the control mice. However, ellagic acid treatment was found to effectively inhibit the cirrhosis degree compared with the model mice (Fig. 3). These data suggest that ellagic acid remitted hepatic histopathological changes and thus may be a novel therapeutic option for the treatment of cirrhosis.

Ellagic acid reduces collagen I gene expression in $\mathrm{CCl}_{4}$-induced cirrhosis mice. The collagen I gene expression in $\mathrm{CCl}_{4}$-induced cirrhosis model mice was detected by PCR analysis and found to be significantly increased compared with the control group (Fig. 4; $\mathrm{P}=0.0021$ ). However, treatment with ellagic acid effectively inhibited the collagen I gene expression in cirrhosis mice (Fig. 4; $\mathrm{P}=0.0056$ ). These data suggest that ellagic acid reduced collagen I gene expression and may thus be used to treat cirrhosis.

Ellagic acid inhibits iNOS protein expression in $\mathrm{CCl}_{4}$-induced cirrhosis mice. iNOS protein expression in tissue samples is shown in Fig. 5. $\mathrm{CCl}_{4}$ significantly induced iNOS protein

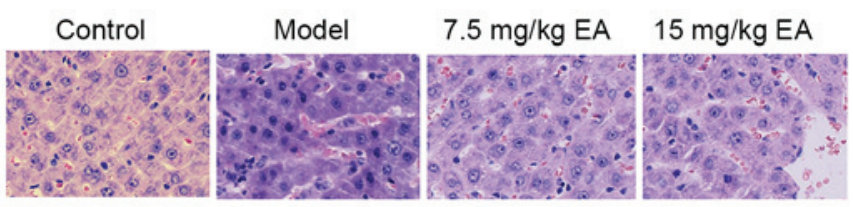

Figure 3. Hematoxylin and eosin staining of liver tissue samples from all groups, showing the protective effect of EA treatment against cirrhosis in mice (magnification, x10). EA, ellagic acid.

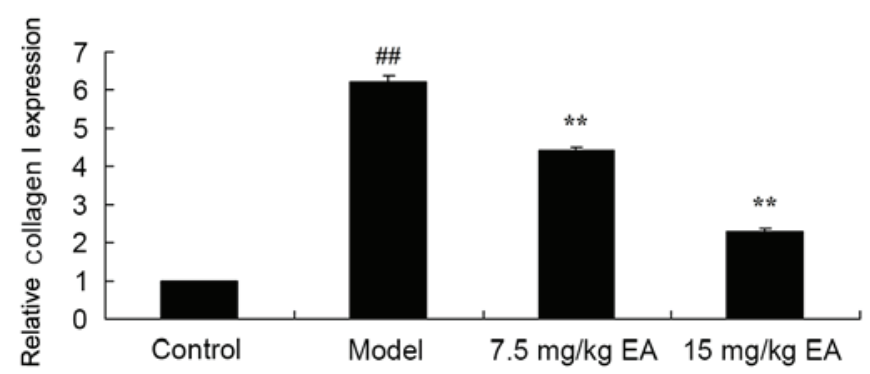

Figure 4. Collagen I gene expression in liver tissues of $\mathrm{CCl}_{4}$-induced cirrhosis mice treated with EA, as determined by polymerase chain reaction. ${ }^{\# \#} \mathrm{P}<0.01$ vs. control group; ${ }^{* *} \mathrm{P}<0.01$ vs. model group. $\mathrm{CCl}_{4}$, tetrachloride; EA, ellagic acid.

expression in cirrhosis mice, compared with that of the control group $(\mathrm{P}=0.0023)$. However, administration of ellagic acid significantly suppressed the protein expression of iNOS in cirrhosis mice (Fig. 5; $\mathrm{P}=0.0081$ and 0.0066). These data suggested that the protective effects of ellagic acid may prevent against $\mathrm{CCl}_{4}$-induced cirrhosis through the suppression of iNOS expression.

Protective effect of ellagic acid against oxidative stress in $\mathrm{CCl}_{4}$-induced cirrhosis mice. $\mathrm{CCl}_{4}$ administration to induce cirrhosis in mice was observed to inhibit the activities of GSH-PX ( $\mathrm{P}=0.0022)$, GSH ( $\mathrm{P}=0.0034)$ and SOD ( $\mathrm{P}=0.0037)$, whereas it increased the MDA ( $\mathrm{P}=0.0014)$ level in cirrhosis mice, when compared with the control group levels (Fig. 6). By contrast, treatment with ellagic acid for 5 weeks significantly reversed the GSH-PX ( $\mathrm{P}=0.0082$ and 0.0037$)$, GSH $(\mathrm{P}=0.0065$ and 0.0024$)$, SOD $(\mathrm{P}=0.0056$ and 0.0029$)$ and MDA ( $\mathrm{P}=0.0052$ and 0.0041$)$ activities in cirrhosis mice (Fig. 6). These data suggest that ellagic acid may have anti-oxidative effects and thus be used in the treatment of cirrhosis.

Protective effect of ellagic acid against ROS formation in $\mathrm{CCl}_{4}$-induced cirrhosis mice. ROS formation was determined in order to evaluate the protective effect of ellagic acid against $\mathrm{ROS}$ formation in $\mathrm{CCl}_{4}$-induced cirrhosis mice. The ROS formation was significantly increased in the untreated cirrhosis mice compared with that of the control group (Fig. 7; $\mathrm{P}=0.0023)$. However, administration of 7.5 or $15 \mathrm{mg} / \mathrm{kg}$ ellagic acid significantly inhibited ROS formation in the cirrhosis mice (Fig. 7; $\mathrm{P}=0.0062$ and 0.0046 ). These data indicated that ellagic acid suppressed ROS formation to inhibit oxidative stress in mice with $\mathrm{CCl}_{4}$-induced cirrhosis. 

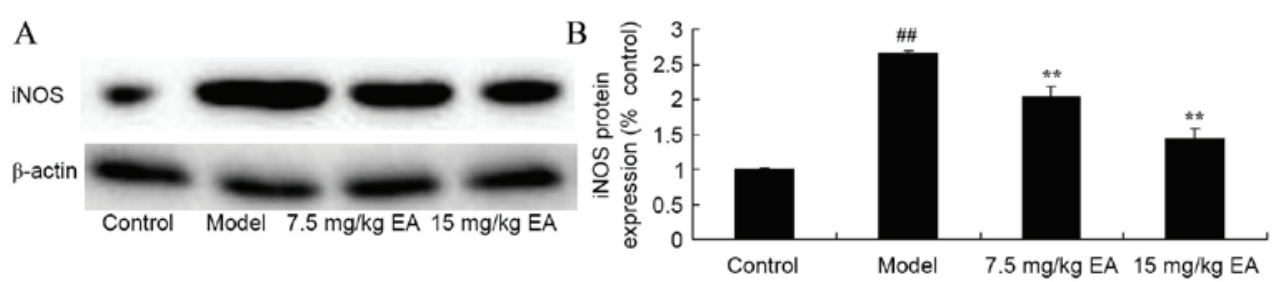

Figure 5. iNOS protein expression in $\mathrm{CCl}_{4}$-induced cirrhosis mice. (A) Western blots and (B) quantified levels of iNOS protein expression are shown. ${ }^{\sharp \#} \mathrm{P}<0.01$ vs. control group; ${ }^{* *} \mathrm{P}<0.01$ vs. model group. $\mathrm{CCl}_{4}$, tetrachloride; EA, ellagic acid; iNOS, inducible nitric oxide synthase.
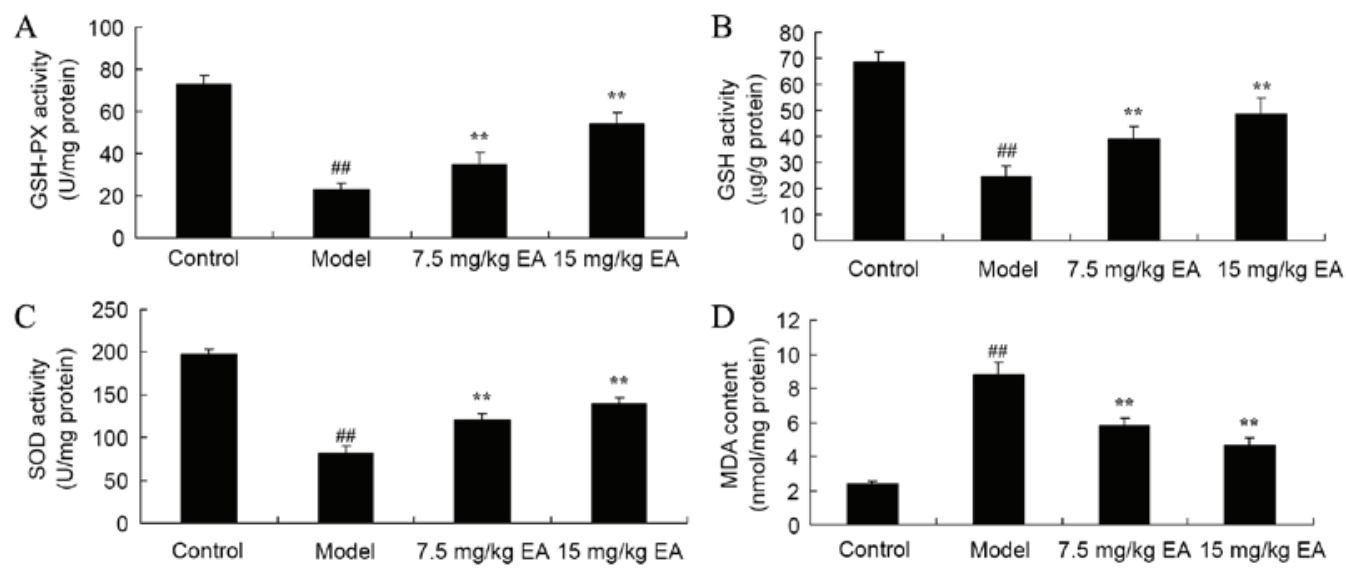

Figure 6. Protective effects of ellagic acid against oxidative stress in $\mathrm{CCl}_{4}$-induced cirrhosis mice. The activities of (A) GSH-PX, (B) GSH, (C) SOD and (D) MDA were determined by ELISA kits. ${ }^{\# /} \mathrm{P}<0.01$ vs. control group; ${ }^{* * *} \mathrm{P}<0.01$ vs. model group. $\mathrm{CCl}_{4}$, tetrachloride; EA, ellagic acid; GSH-Px, glutathione peroxidase; GSH, glutathione; SOD, superoxide dismutase; MDA, malondialdehyde.

Ellagic acid treatment reduces VEGF expression in $\mathrm{CCl}_{4}$-induced cirrhosis mice. In addition, the present study examined the mechanism of ellagic acid against VEGF expression in $\mathrm{CCl}_{4}$-induced cirrhosis mice by western blot analysis. A significant decrease in VEGF protein expression was identified in the cirrhosis model mice, compared with the control group (Fig. 8; $\mathrm{P}=0.0023$ ). However, treatment with ellagic acid significantly induced the VEGF protein expression in the cirrhosis mice (Fig. 8; $\mathrm{P}=0.0076$ and 0.0037).

Ellagic acid treatment reduces VEGFR2 expression in $\mathrm{CCl}_{4}$-induced cirrhosis mice. The protective effect of ellagic acid against VEGFR2 expression in $\mathrm{CCl}_{4}$-induced cirrhosis mice was further investigated using western blot analysis. As shown in Fig. 9, the protein expression of VEGFR2 in cirrhosis model mice was significantly higher compared with that of the control group $(\mathrm{P}=0.0027)$. Treatment with 7.5 and $15 \mathrm{mg} / \mathrm{kg}$ ellagic acid significantly decreased the protein expression of VEGFR2 in the cirrhosis mice (Fig. 9; $\mathrm{P}=0.0059$ and 0.0043 ). These data indicate that ellgaic acid may function via VEGF to exert its protective effects against cirrhosis.

Ellagic acid treatment reduces caspase-3 activity in $\mathrm{CCl}_{4}$-induced cirrhosis mice. The anti-apoptosis effect of ellagic acid treatment against cirrhosis in mice was examined by recording the caspase- 3 activity using an ELISA kit. Compared with the control group, the caspase- 3 activity was significantly enhanced in cirrhosis model mice (Fig. 10; $\mathrm{P}=0.0013)$. Treatment with ellagic acid, however, significantly

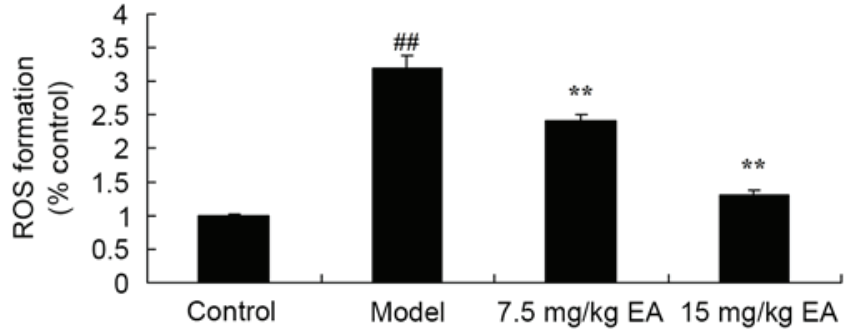

Figure 7. Protective effects of ellagic acid against ROS formation in $\mathrm{CCl}_{4}$-induced cirrhosis mice. ${ }^{\#} \mathrm{P}<0.01$ vs. control group; ${ }^{* *} \mathrm{P}<0.01$ vs. model group. $\mathrm{CCl}_{4}$, tetrachloride; EA, ellagic acid; ROS, reactive oxygen species.

reduced caspase-3 activity in the cirrhosis mice (Fig. 10; $\mathrm{P}=0.0041$ and 0.0026 ).

\section{Discussion}

Acute hepatic failure based on liver cirrhosis is common (15). However, due to acute injury factors, such as quick replication of hepatitis virus and damage resulting from virulence drugs and ethyl alcohol, the liver function is worsened in a short period of time, with hemorrhage, infection, hepatic encephalopathy and high mortality rates (4). The results of the present study demonstrated that ellagic acid treatment effectively inhibited the serum levels of ALT, AST and ALB, as well as the collagen I gene expression, in cirrhosis mice.

Stress is considered as an important factor of liver injury. As far as oxidative stress is concerned, due to injuries of 

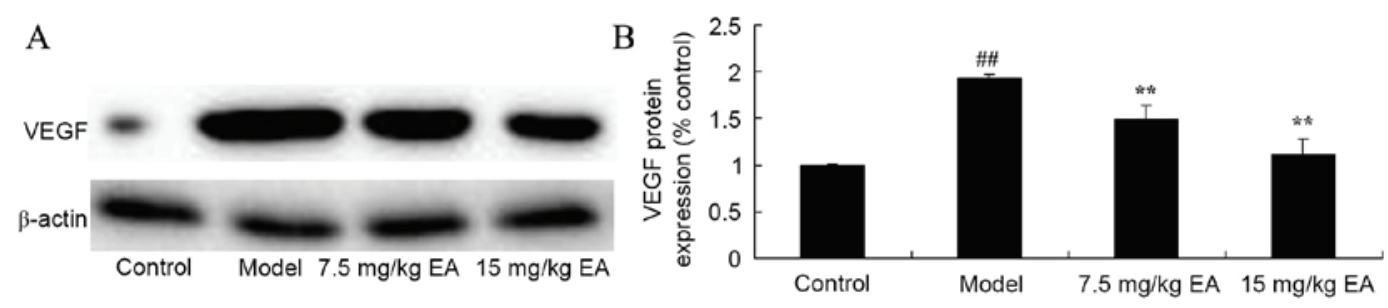

Figure 8. VEGF protein expression in $\mathrm{CCl}_{4}$-induced cirrhosis mice. (A) Western blots and (B) quantified levels showed reduced VEGF protein expression following EA treatment. ${ }^{\# \#} \mathrm{P}<0.01$ vs. control group; ${ }^{* *} \mathrm{P}<0.01$ vs. model group. $\mathrm{CCl}_{4}$, tetrachloride; EA, ellagic acid; VEGF, vascular endothelial growth factor.
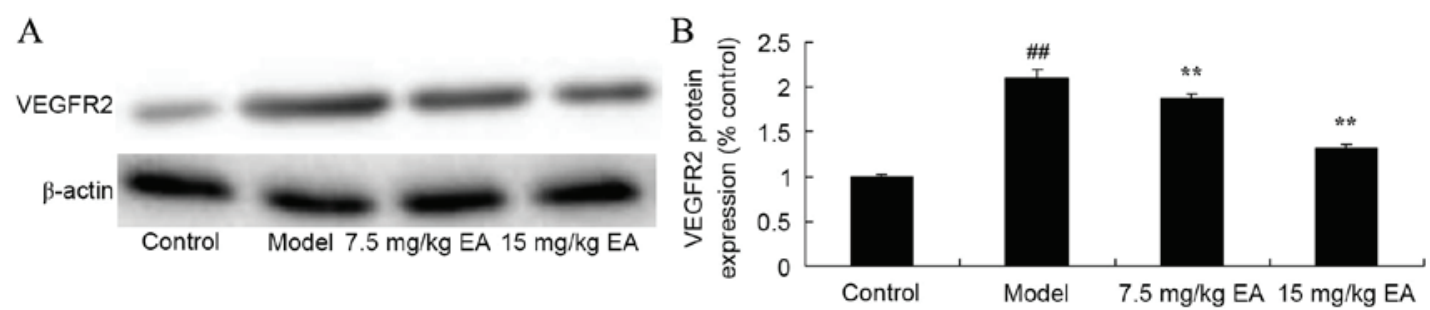

Figure 9. VEGFR2 protein expression in $\mathrm{CCl}_{4}$-induced cirrhosis mice. (A) Western blots and (B) quantified levels showed reduced VEGFR2 protein expression following EA treatment. ${ }^{\# \#} \mathrm{P}<0.01$ vs. control group; ${ }^{* *} \mathrm{P}<0.01$ vs. model group. $\mathrm{CCl}_{4}$, tetrachloride; EA, ellagic acid; VEGFR2, vascular endothelial growth factor receptor 2 .

hyperfunction and damages of the antioxidation mechanisms, polymer reactions occur after free radicals, active oxygen and proteins, lipids and nucleic acids $(10,16)$. It has been reported that oxidative stress is also closely associated with hepatocellular injury (17). SOD is the main protective enzyme in the anti-oxidation system, which can catalyze the disproportion reaction of the superoxide anion and prevent damages to tissues caused by the superoxide anion (18). In addition, GSH is an effective free-radical scavenger, inhibiting the launch and development of lipid peroxidation, while MDA is the end-product of cytomembrane lipid peroxidation. The levels of these indicators are abnormal under oxidative stress (10). In the current study, treatment with ellagic acid significantly suppressed iNOS protein expression, reversed the GSH-PX, GSH, SOD and MDA activities, and inhibited ROS formation in cirrhosis mice. Ural et al (12) have suggested that treatment with ellagic acid protects against malathion exposure through reducing oxidative stress and antioxidant status in Cyprinus carpio.

VEGF induces vasculogenesis and endothelial cell proliferation and has important functions in the regulation of angiogenesis (19). In recent years, VEGF has been proven to promote the formation of endothelial cells, and increase the permeability of endothelial and glomerular cells (20). Trigger point injection of VEGF promotes the formation of new vessels surrounding the sinus hepaticus in normal or liver cirrhosis mice (21). A previous study has proven that expression levels of VEGF in patients or test models are increased and can worsen liver cirrhosis (22). In liver cirrhosis mice subsequent to hepatectomy, VEGF effectively promotes liver regeneration $(23,24)$. In the present study, ellagic acid treatment significantly induced the VEGF and VEGFR2 protein expression levels in cirrhosis mice. Similarly, Labrecque et al (25) reported that ellagic acid may be helpful for the prevention and treatment of cancer through decreasing platelet-derived growth factor and VEGF receptors.

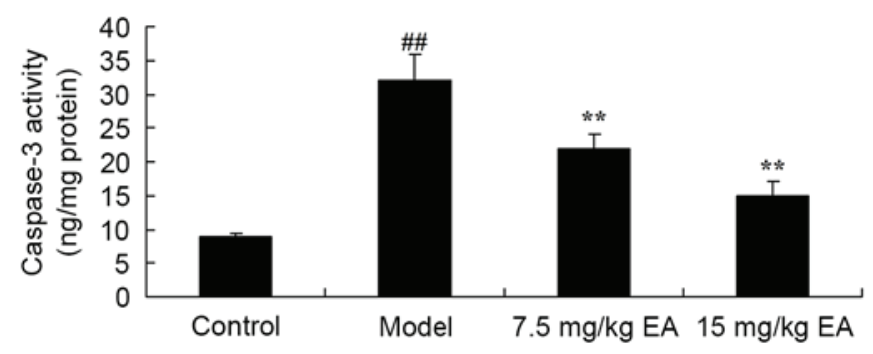

Figure 10. Caspase-3 activity in $\mathrm{CCl}_{4}$-induced cirrhosis mice. EA treatment significantly reduced the caspase-3 levels. ${ }^{\# \#} \mathrm{P}<0.01$ vs. control group; ${ }^{* *} \mathrm{P}<0.01$ vs. model group. $\mathrm{CCl}_{4}$, tetrachloride; EA, ellagic acid.

Caspases are a group of apoptosis proteases. According to the effects of caspases in cell apoptosis, they can be divided into upstream and downstream caspases (26). Caspase-3, located on the common pathway of cell apoptosis, is the most important member of the caspase family, and the majority of factors causing apoptosis (27). Signal transduction pathways mediated by caspase-3 result in cell apoptosis, and the expression levels of caspase- 3 can positively represent the apoptosis levels of the tissues $(27,28)$. The current study findings indicated that ellagic acid significantly reduced caspase-3 activity in cirrhosis mice, thus suggesting that apoptosis was inhibited. Mishra et al (13) also reported that ellagic acid promotes apoptosis in lymphoma-bearing mice through an increase ofcaspase-3.

In conclusion, the present study demonstrated that the protective effects of ellagic acid inhibited the serum levels of ALT, AST and ALB, as well as collagen I gene expression, in cirrhosis mice. These protective effects are associated with the antioxidative mechanisms, and the inhibition of iNOS and caspase- 3 expression, and induction VEGF expression in cirrhosis mice. Thus, it is suggested that ellagic acid may be a potential new drug under hypoxic conditions in CCl4-induced cirrhosis through the inhibition of ROS formation and angiogenesis. 


\section{References}

1. Patin E, Kutalik Z, Guergnon J, Bibert S, Nalpas B, Jouanguy E, Munteanu M, Bousquet L, Argiro L, Halfon P, et al: Genome-wide association study identifies variants associated with progression of liver fibrosis from HCV infection. Gastroenterology 143: 1244-1252.e1-e12, 2012.

2. Caprai S, Vajro P, Ventura A, Sciveres M and Maggiore G; SIGENP Study Group for Autoimmune Liver Disorders in Celiac Disease: Autoimmune liver disease associated with celiac disease in childhood: A multicenter study. Clin Gastroenterol Hepatol 6: 803-806, 2008.

3. Assy N, Kayal M, Mejirisky Y, Gorenberg M, Hussein O and Schlesinger S: The changes in renal function after a single dose of intravenous furosemide in patients with compensated liver cirrhosis. BMC Gastroenterol 6: 39, 2006.

4. Kuiper EM, Hansen BE, Lesterhuis W, Robijn RJ, Thijs JC, Engels LG, Koek GH, Aparicio MN, Kerbert-Dreteler MJ and van Buuren HR; Dutch PBC study group: The long-term effect of ursodeoxycholic acid on laboratory liver parameters in biochemically non-advanced primary biliary cirrhosis. Clin Res Hepatol Gastroenterol 35: 29-33, 2011.

5. Mišík M, Hoelzl C, Wagner KH, Cavin C, Moser B, Kundi M, Simic T, Elbling L, Kager N, Ferk F, et al: Impact of paper filtered coffee on oxidative DNA-damage: Results of a clinical trial. Mutat Res 692: 42-48, 2010.

6. Spahr L, Bresson-Hadni S, Amann P, Kern I, Golaz O, Frossard JL and Hadengue A: Allopurinol, oxidative stress and intestinal permeability in patients with cirrhosis: An open-label pilot study. Liver Int 27: 54-60, 2007.

7. Simón-Talero M, Garcia-Martinez R, Torrens M, Augustin S, Gómez S, Pereira G, Guevara M, Ginés P, Soriano G, Román E, et al: Effects of intravenous albumin in patients with cirrhosis and episodic hepatic encephalopathy: A randomized double-blind study. J Hepatol 59: 1184-1192, 2013.

8. Deng G, Wang J, Zhang Q, He H, Wu F, Feng T, Zhou J, Zou K and Hattori M: Hepatoprotective effects of phloridzin on hepatic fibrosis induced by carbon tetrachloride against oxidative stress-triggered damage and fibrosis in rats. Biol Pharm Bull 35: $1118-1125,2012$.

9. Fang H, Liu A, Dirsch O and Dahmen U: Liver transplantation and inflammation: Is lipopolysaccharide binding protein the link? Cytokine 64: 71-78, 2013.

10. Marotta F, Yoshida C, Barreto R, Naito Y and Packer L: Oxidative-inflammatory damage in cirrhosis: Effect of vitamin $\mathrm{E}$ and a fermented papaya preparation. J Gastroenterol Hepatol 22 697-703, 2007

11. Nutan, Modi M, Goel T, Das T, Malik S, Suri S, Rawat AK, Srivastava SK, Tuli R, Malhotra S and Gupta SK: Ellagic acid \& gallic acid from Lagerstroemia speciosa L. inhibit HIV-1 infection through inhibition of HIV-1 protease \& reverse transcriptase activity. Indian J Med Res 137: 540-548, 2013.

12. Ural MSs, Yonar ME and Mişe Yonar S: Protective effect of ellagic acid on oxidative stress and antioxidant status in Cyprinus carpio during malathion exposure. Cell Mol Biol (Noisy-le-grand) 61: 58-63, 2015.

13. Mishra S and Vinayak M: Role of ellagic acid in regulation of apoptosis by modulating novel and atypical PKC in lymphoma bearing mice. BMC Complement Altern Med 15: 281, 2015.
14. Zhang HM, Zhao L, Li H, Xu H, Chen WW and Tao L: Research progress on the anticarcinogenic actions and mechanisms of ellagic acid. Cancer Biol Med 11: 92-100, 2014

15. De Minicis S and Brenner DA: Oxidative stress in alcoholic liver disease: Role of NADPH oxidase complex. J Gastroenterol Hepatol 23 (Suppl 1): S98-S103, 2008.

16. Oettl K, Stadlbauer V, Petter F, Greilberger J, Putz-Bankuti C, Hallström S, Lackner C and Stauber RE: Oxidative damage of albumin in advanced liver disease. Biochim Biophys Acta 1782: 469-473, 2008

17. Vidali M, Occhino G, Ivaldi A, Rigamonti C, Sartori M and Albano E: Combination of oxidative stress and steatosis is a risk factor for fibrosis in alcohol-drinking patients with chronic hepatitis C. Am J Gastroenterol 103: 147-153, 2008.

18. Li J and Wang Y: Effect of different methods of hypoxic exercise training on free radical oxidation and antioxidant enzyme activity in the rat brain. Biomed Rep 1: 925-929, 2013.

19. Yan Z, Qu K, Zhang J, Huang Q, Qu P, Xu X, Yuan P, Huang X, Shao Y, Liu C, et al: CD147 promotes liver fibrosis progression via VEGF-A/VEGFR2 signalling-mediated cross-talk between hepatocytes and sinusoidal endothelial cells. Clin Sci (Lond) 129: 699-710, 2015.

20. Tekkesin N, Taga Y, Sav A, Almaata I and Ibrisim D: Induction of HGF and VEGF in hepatic regeneration after hepatotoxin-induced cirrhosis in mice. Hepatogastroenterology 58: 971-979, 2011.

21. Kishta SA, Abd-Alhade AA, Hamam O, Raoof EA and Abeya S: Prognostic value of TNF a mRNA and VEGF mRNA expression in patients with chronic hepatitis $\mathrm{C}$ genotype-4, with and without cirrhosis and hepatocellular carcinoma to predict disease outcome. J Egypt Soc Parasitol 40: 515-530, 2010.

22. Jaroszewicz J, Januszkiewicz M, Flisiak R, Rogalska M, Kalinowska A and Wierzbicka I: Circulating vascular endothelial growth factor and its soluble receptors in patients with liver cirrhosis: Possible association with hepatic function impairment. Cytokine 44: 14-17, 2008.

23. Mukozu T, Nagai H, Matsui D, Kanekawa T and Sumino $Y$ Serum VEGF as a tumor marker in patients with HCV-related liver cirrhosis and hepatocellular carcinoma. Anticancer Res 33: 1013-1021, 2013.

24. Surapaneni KM, Vishnu Priya V and Mallika J: Effect of pioglitazone, quercetin, and hydroxy citric acid on vascular endothelial growth factor messenger RNA (VEGF mRNA) expression in experimentally induced nonalcoholic steatohepatitis (NASH). Turk J Med Sci 45: 542-546, 2015.

25. Labrecque L, Lamy S, Chapus A, Mihoubi S, Durocher Y, Cass B, Bojanowski MW, Gingras D and Béliveau R: Combined inhibition of PDGF and VEGF receptors by ellagic acid, a dietary-derived phenolic compound. Carcinogenesis 26: 821-826, 2005.

26. Izawa T, Horiuchi T, Atarashi M, Kuwamura M and Yamate J: Anti-fibrotic Role of miR-214 in Thioacetamide-induced liver cirrhosis in rats. Toxicol Pathol 43: 844-851, 2015.

27. Liu C, Wang G, Chen G, Mu Y, Zhang L, Hu X, Sun M, Liu C and Liu P: Huangqi decoction inhibits apoptosis and fibrosis, but promotes Kupffer cell activation in dimethylnitrosamine-induced rat liver fibrosis. BMC Complement Altern Med 12: 51, 2012

28. Wu XX, Wu LM, Fan JJ, Qin Y, Chen G, Wu XF, Shen Y, Sun Y and Xu Q: Cortex Dictamni extract induces apoptosis of activated hepatic stellate cells via STAT1 and attenuates liver fibrosis in mice. J Ethnopharmacol 135: 173-178, 2011. 